\footnotetext{
Revista Española de Derecho Internacional

Sección PRÁCTICA ESPAÑOLA DE DERECHO INTERNACIONAL Vol. 71/2, julio-diciembre 2019, Madrid, pp. 311-317 http://dx.doi.org/10.17103/redi.71.2.2019.3.01 (C) 2019 Asociación de Profesores de Derecho Internacional y Relaciones Internacionales ISSN: 0034-9380; E-ISSN: 2387-1253 Recepción 05.05.2019, aceptación 07.05.2019
}

\author{
III. PRÁCTICA ESPAÑOLA \\ DE DERECHO \\ INTERNACIONAL
}

\title{
LA JURISDICCIÓN UNIVERSAL ESPAÑOLA EN LA STC 140/2018, DE 20 DE DICIEMBRE
}

\author{
Maria Chiara MARULLO*
}

1. La sentencia merecería ser analizada desde diferentes perspectivas, en las que por las limitaciones de este comentario no podremos profundizar, que incluyen cuestiones tanto de Derecho internacional como de Derecho interno español. Pero debemos decir desde ahora que, en un momento como el que estamos viviendo, de fuerte retroceso en términos de protección de los derechos humanos y en el que el Tribunal Penal Internacional enfrenta importantes desafíos, destaca la trayectoria adoptada por los legisladores españoles, que han venido obstaculizando el ejercicio de una jurisdicción universal como mecanismo para garantizar un foro, en muchos casos de necesidad, para las víctimas de atroces crímenes, cuando pueda entrar en conflicto con intereses económicos, políticos o diplomáticos. Esta trayectoria seguramente menoscaba las oportunidades de justicia real de dichas víctimas, desamparadas en el Estado donde se verificaron los hechos delictivos y sin acceso a los tribunales internacionales.

2. El pasado 20 de diciembre el Tribunal Constitucional dictó sentencia desestimando el recurso de inconstitucionalidad planteado por 50 diputados del Grupo Parlamentario Socialista contra la reforma introducida con la Ley Orgánica 1/2014, publicada en marzo de 2014, promulgada, según los recurrentes, bajo enormes presiones internacionales, por la que se restringe el alcance del sistema de jurisdicción universal, regulada en la Ley Orgánica del Poder Judicial 6/1985. Cabe mencionar que este sistema había sido previamente modificado y que, en el año 2009, la jurisdicción universal fue limitada al exigir requisitos para activarla. Con la nueva reforma en el año 2014, el legislador optó por restringir aún más este sistema, introduciendo puntos de conexión específicos para cada delito internacional y, en particular, para los delitos de genocidio, de lesa humanidad o contra las personas y bienes protegidos en caso de conflicto armado, estableciéndose que el procedimiento

* Profesora Ayudante Doctor de Derecho Internacional Privado (Acreditada a Contratada Doctora), Universitat Jaume I, marullo@uji.es. 
debe dirigirse contra un ciudadano español, contra un extranjero residente en España o contra un extranjero presente en territorio español cuya extradición se deniegue. Asimismo, con su norma transitoria, supuso de facto el archivo de casi todos los procedimientos existentes en la Audiencia Nacional y en el Tribunal Supremo que no cumplían con los nuevos requisitos establecidos.

3. El Tribunal Constitucional avala que la jurisdicción universal pueda ser alterada, y por tanto también limitada, por el legislador español, ya que no puede deducirse a nivel internacional la existencia de un modelo único, general y obligatorio de competencia de los tribunales estatales para la represión penal extraterritorial de crímenes internacionales. Tras un análisis del desarrollo internacional del principio en cuestión, el Alto Tribunal concluye, además, que los tratados que prohíben determinadas conductas delictivas internacionales y establecen mecanismos para su persecución no imponen una obligación de ejercer una jurisdicción universal, sino una mera facultad. Por todo ello, los legisladores nacionales, que son los encargados de determinar el marco jurídico concreto para su aplicación, pueden decidir limitar su ejercicio especialmente en lo que respecta a los requisitos de admisibilidad del recurso, estableciendo, en su caso, puntos de contacto para su activación.

4. En nuestra opinión, la sentencia evidencia, una vez más, que el ejercicio de una jurisdicción extraterritorial sobre la base de una competencia universal sigue siendo un problema abierto a un amplio debate, debido a numerosas cuestiones que no han sido resueltas por el Derecho internacional. Pesa, asimismo, la falta de una praxis estatal orientada hacia la creación de un modelo único y obligatorio, junto con la ausencia de un posicionamiento claro sobre el tema del alcance y eventual obligatoriedad del principio de jurisdicción universal por parte de los órganos internacionales que, habiendo tenido en muchas ocasiones la oportunidad de pronunciarse sobre él, han decidido no hacerlo.

5. Antes de pasar al análisis de los puntos más relevantes de esta decisión, cabe mencionar el impacto jurídico que ya ha tenido, puesto que el Tribunal Constitucional está marcando una dirección clara de cierre, sobre todo en lo referente a la aplicación de la disposición transitoria única, si no se dan los requisitos que establece el nuevo art. 23.4 LOPJ para la atribución de la competencia universal. Véanse, por ejemplo, sus sentencias posteriores en los casos Falun Gong ${ }^{1}$, recurso de amparo promovido por doña Z. D. y otras catorce personas más, en relación con las resoluciones de la Sala de lo Penal del Tribunal Supremo y de la Audiencia Nacional que acordaron el sobreseimiento y archivo, por falta de jurisdicción de los tribunales españoles, de la querella presentada en relación con los posibles delitos de genocidio y torturas que habrían padecido los miembros del movimiento espiritual denominado Falun Gong; el recurso de amparo promovido por la asociación Comité de Apoyo al Tíbet ${ }^{2}$, en relación con las resoluciones de la Sala de lo

\footnotetext{
1 STC 10/2019, de 28 de enero.

2 STC 23/2019, de 25 de febrero.
} 
Penal del Tribunal Supremo y de la Audiencia Nacional que acordaron el sobreseimiento y archivo, por falta de jurisdicción de los tribunales españoles, de la querella presentada en relación con los posibles delitos de genocidio, torturas, terrorismo y lesa humanidad, que se habrían cometido en la región autónoma del Tíbet, a pesar de incluir un caso de torturas cometido contra una víctima española, Thubten Wangchen que no ostentaba esta nacionalidad en el momento de la comisión de los hechos; y la inadmisión del recurso de amparo promovido por don Seyez Morteza Komarizadehasl y Mohammad Reza Mohade ${ }^{3}$ en relación al archivo, por falta de jurisdicción, de la querella presentada en relación a los posibles delitos contra la Comunidad Internacional que se habrían cometido en el campo de refugiados de Ashraf en Irak.

6. Entrando en el análisis de la sentencia podemos ver cómo los recurrentes impugnan la totalidad de la Ley Orgánica 1/2014, desde su tramitación hasta diversas cuestiones materiales. Las críticas formuladas relativas a la tramitación parlamentaria fueron:

«1) La opción por presentar una proposición de ley habría impedido que la iniciativa fuera acompañada de los informes y dictámenes que deben emitir determinados órganos e instituciones cuando se presenta un proyecto de ley de conformidad con lo dispuesto en el art. 88 CE. [...]. 2) Se limitó el debate parlamentario porque la proposición de ley fue objeto de una tramitación particularmente acelerada».

En relación con las cuestiones materiales, los recurrentes consideran que la nueva reglamentación es regresiva y desnaturaliza el principio de jurisdicción universal (art. $10 \mathrm{CE}$ ), atenta contra los principios de interdicción de la arbitrariedad y seguridad jurídica (art. 9.3 CE) resultando además contraria al derecho de tutela judicial efectiva (art. $24 \mathrm{CE}$ ), y que el acceso a la jurisdicción no se garantizaría en condiciones de igualdad para todos los ciudadanos españoles (art. $14 \mathrm{CE}$ ) vulnerando, asimismo, el art. $96 \mathrm{CE}$, porque se alterarían las obligaciones internacionales ratificadas por España. En particular, la nueva formulación del art. 23.4.a) LOPJ sería contraria a lo dispuesto en el IV Convenio de Ginebra de Protección de Personas Civiles en Tiempo de Guerra. Finalmente, los recurrentes critican la ausencia de la posibilidad de una acción popular en la persecución de delitos internacionales y la disposición transitoria en relación con el principio de interdicción de la retroactividad, al prever su aplicación a procedimientos iniciados con anterioridad a la reforma.

7. Por su parte, la Abogacía del Estado solicita la desestimación de la demanda, negando la arbitrariedad, así como la ausencia de seguridad jurídica y la desnaturalización del principio de jurisdicción universal, descartando además la lesión del derecho al acceso a la jurisdicción de las víctimas españolas y negando que la nueva formulación contradiga los tratados internacionales ratificados por España.

\footnotetext{
3 STC 15/2019, de 11 de febrero.
} 
8. Sobre los motivos de inconstitucionalidad formal, este Tribunal ha establecido que:

«Las quejas relativas al procedimiento legislativo contenidas en la demanda no pueden ser reconducidas a causa de inconstitucionalidad alguna, poniendo de relieve el mero disenso político con el modo y el transcurrir de la tramitación parlamentaria, disenso que no tiene por qué hallar traducción en términos de inconstitucionalidad formal de la ley».

En relación con las cuestiones materiales, este Tribunal establece la constitucionalidad de la nueva formulación de la LOPJ sobre la competencia de la jurisdicción española para la represión penal extraterritorial de delitos internacionales.

9. Tras una lectura detenida, consideramos que dos cuestiones merecen un especial análisis: el tema de la permisibilidad de la jurisdicción universal con arreglo al Derecho internacional y la doctrina del control de convencionalidad o control difuso. Comenzando con la primera cuestión, cabe mencionar que los problemas relativos a este sistema no son nuevos para el Tribunal Constitucional. Con anterioridad ya había sido llamado a pronunciarse sobre su permisibilidad y los requisitos estatales con arreglo al Derecho internacional, en particular con aquellas normas internacionales creadas para velar por los intereses superiores de la Comunidad Internacional, y sobre la prohibición de determinadas conductas delictivas que afectan al propio concepto de paz y seguridad internacional. Concretamente, en el año $2005^{4}$ apostó por un sistema de jurisdicción universal absoluto sin condicionamientos, salvo el relativo al principio non bis in idem. La capacidad de los tribunales nacionales de ejercer su competencia en relación con la jurisdicción de la Comunidad Internacional sobre determinados delicta juris gentium se configuraba como una herramienta para la lucha contra la impunidad para garantizar la tutela judicial efectiva, entendida en base al acceso a los tribunales. Siguiendo esta orientación, la aplicación de una competencia para conocer y juzgar a los responsables de determinados delitos que ofenden a la Humanidad en su conjunto por parte de un Estado, sin que concurran otros criterios de conexión entre los hechos y los tribunales del foro, se fundamentaría en la jurisdicción de la Comunidad Internacional para el restablecimiento del orden internacional violado; una forma de actio popularis en defensa de los intereses de dicha Comunidad. Un modelo de competencia universal absoluto que, seguramente, resultaba útil y necesario para asegurar el cumplimiento de las obligaciones internacionales erga omnes establecidas en los tratados internacionales y que, al mismo tiempo, daría efectividad a las prohibiciones allí recogidas.

10. Esos tratados establecen que la jurisdicción territorial es un deber para los Estados en cuyo territorio se verificaron los hechos. Pero, a falta de la voluntad o de la capacidad de dichos tribunales, y teniendo en cuenta que la única prohibición internacional sobre el ejercicio de la jurisdicción

\footnotetext{
${ }^{4}$ STC $237 / 2005$, de 26 de septiembre.
} 
penal se refiere a la jurisdicción penal ejecutiva en el territorio de otro Estado sin su autorización y respetando el principio de complementariedad con la jurisdicción internacional establecida, entendemos que la competencia para juzgar determinados delitos internacionales se debería considerar universal. En otras palabras, lejos de negar o limitar la jurisdicción de los Estados en cuyo territorio se verificaron los hechos o el ejercicio de la jurisdicción internacional de los tribunales internacionales creados para conocer determinados crímenes, el Derecho internacional necesita que los órganos legislativos y judiciales de todos los Estados actúen en determinadas circunstancias para imponer efectivamente las prohibiciones internacionales antes mencionadas y enjuiciar a quienes las violen. Solamente de esta forma se mantendría el llamado principio del desdoblamiento funcional del Derecho internacional, impidiendo que esas normas se convirtiesen en papel mojado.

11. No obstante, sobre este punto, en la sentencia que comentamos se afirma que la nueva formulación introducida en la LOPJ 1/2014, que sigue la línea limitativa de la precedente regulación en el año 2009 y que diseñaba una jurisdicción universal condicionada, no contradice los principios antes mencionados. Estas modificaciones, entonces, no supondrían un cierre para la aplicación de la jurisdicción universal por parte de los tribunales españoles, que podrán activarla siempre que concurran determinados requisitos. Dichos requisitos responden a la exigencia de adecuar la respuesta de los tribunales nacionales a las prescripciones de la Comunidad Internacional, respetando los principios de subsidiariedad y de complementariedad con los órganos que tienen competencias específicas sobre determinados delitos internacionales.

12. Así, el Tribunal Constitucional sostiene que cuando hablamos de jurisdicción extraterritorial lo hacemos sobre la capacidad de los Estados de establecer normas prescriptivas penales sobre determinadas conductas delictivas que se han podido verificar en el territorio de otro Estado, y de velar por su observancia mediante sus propios tribunales. Esto conllevaría la admisión de que los legisladores son quienes determinan el alcance de dichas normas y los requisitos para su aplicación, pudiendo restringirla o limitarla a determinadas conductas o exigiendo una conexión entre los hechos y el foro. Con todo, en la misma sentencia se evidencia cómo en esta tarea los legisladores no son totalmente libres a la hora de configurar las opciones normativas, ya que están obligados a respetar los límites constitucionales, como el de garantizar el acceso a la jurisdicción, conforme a los tratados internacionales. Pese a ello, no se deduce que el modelo diseñado por la nueva regulación del art. 23.4 LOPJ resulte lesivo para el derecho de acceso a la justicia recogido en la Constitución Española, ya que los tratados internacionales no establecen un modelo único, general y obligatorio de jurisdicción universal. Algo que encuentra confirmación en los pronunciamientos de destacados órganos internacionales y en la falta de opinio iuris en la praxis estatal.

13. Pasamos al segundo punto, el control de convencionalidad o difuso. Aquí, la doctrina sentada podría suponer un avance importante en términos de justicia real para las víctimas de delitos internacionales, ya que el Tribunal 
menciona de manera explícita ese control, abriendo la puerta a la competencia del juez ordinario para dar efectividad al principio de superioridad de los tratados sobre las leyes internas. La cuestión del control de convencionalidad y el diálogo entre los tribunales nacionales e internacionales se aborda en el FJ 6 sobre la base de la previsión contenida en el art. 96 de la CE:

«Los tratados internacionales válidamente celebrados, una vez publicados oficialmente en España, formarán parte del ordenamiento interno. Sus disposiciones solo podrán ser derogadas, modificadas o suspendidas en la forma prevista en los propios tratados o de acuerdo con las normas generales del Derecho internacional».

Para dar ejecución a lo dispuesto, cabe mencionar la Ley 25/2014, de 27 de noviembre, de Tratados y otros Acuerdos Internacionales, que establece en su art. 30: «1. Los tratados internacionales serán de aplicación directa, a menos que de su texto se desprenda que dicha aplicación queda condicionada a la aprobación de las leyes o disposiciones reglamentarias pertinentes». Y en su art. 31 se prescribe que: «Las normas jurídicas contenidas en los tratados internacionales válidamente celebrados y publicados oficialmente prevalecerán sobre cualquier otra norma del ordenamiento interno en caso de conflicto con ellas, salvo las normas de rango constitucional». Podríamos decir que el legislador ha establecido un mecanismo de control difuso para que los jueces apliquen este control de convencionalidad.

14. La doctrina del control de convencionalidad se fundamentaría en los principios de pacta sunt servanda y de buena fe en el cumplimiento de los tratados internacionales y, con ello, en la necesidad de tutelar los derechos fundamentales y velar por la efectividad de dicha protección por parte de los órganos jurisdiccionales nacionales. En virtud de estos principios, un Estado parte en un tratado internacional no podría apoyar en una norma interna la inobservancia de lo prevenido en él. De ello se desprende que un juez ordinario, cuando se encuentre con una norma interna contraria a la protección de los derechos humanos establecida en los tratados internacionales, puede como consecuencia directa de lo indicado inaplicar la norma interna, en favor de aquella internacional lesionada.

Esto podría suponer que el juez ordinario sea quien finalmente decida sobre la norma aplicable (la interna o la internacional) sin entrar a determinar la inconstitucionalidad de la primera:

«Cualquier juez ordinario puede desplazar la aplicación de una norma interna con rango de ley para aplicar de modo preferente la disposición contenida en un tratado internacional, sin que de tal desplazamiento derive la expulsión de la norma interna del ordenamiento, como resulta obvio, sino su mera inaplicación al caso concreto".

El Tribunal Constitucional precisa que el art. $96 \mathrm{CE}$ :

«No atribuye superioridad jerárquica a los tratados sobre las leyes internas, aunque establece, de un lado, una regla de desplazamiento por parte del tratado de la norma interna anterior, sin que ello suponga su derogación, y, de otro, define la resistencia del tratado a ser derogado por las disposiciones internas poste- 
riores en el tiempo, sin que esto último suponga la exclusión de la norma interna del ordenamiento nacional, sino su mera inaplicación. Dicho en otros términos, la constatación de un eventual desajuste entre un convenio internacional y una norma interna con rango de ley no supone un juicio sobre la validez de la norma interna, sino sobre su mera aplicabilidad, por lo que no se plantea un problema de depuración del ordenamiento de normas inválidas, sino una cuestión de determinación de la norma aplicable en la solución de cada caso concreto, aplicación que deberá ser libremente considerada por el juez ordinario».

15. Una cuestión de legalidad que podría suponer que un juez ordinario determinase la inaplicación de la nueva regulación del art. 23.4, al entender que las autolimitaciones establecidas a nivel estatal para el ejercicio de esta jurisdicción universal no resultan compatibles con las normas internacionales relativas a la prohibición y enjuiciamiento de determinadas conductas internacionales, por ejemplo cuando se constate que no hay otros foros competentes accesibles para las víctimas de crímenes de guerra, considerando que los convenios de Ginebra dejan libertad a los Estados para la determinación de los mecanismos para perseguir y sancionar a los responsables, pero no permiten dejar sin foro alguno a las víctimas. El Alto Tribunal, por tanto, deja abierta la puerta a la actuación de los tribunales ordinarios, quienes, desde nuestro punto de vista, tendrán la compleja tarea de afrontar la universalidad de la misión del principio de jurisdicción reiteradamente citado y la particularidad de los intereses del Estado español, que es quien proporciona el marco legal para su aplicación.

Palabras clave: sistema de jurisdicción universal, Ley Orgánica 1/2014, acceso a la justicia, control de convencionalidad.

Keywords: system of universal jurisdiction, Ley Orgánica 1/2014, access to justice, conventionality control. 